\title{
Performance Evaluation of Crumb Rubber Asphalt Modified with Silicone-Based Warm Mix Additives
}

\author{
Nonde Lushinga $\mathbb{D}$, , ${ }^{1,2}$ Liping Cao $\mathbb{D}^{1},{ }^{1}$ Zejiao Dong $\mathbb{D},{ }^{1}$ Chen Yang $\mathbb{D}{ }^{1}$ \\ and Cyriaque O. Assogba ${ }^{1}$ \\ ${ }^{1}$ School of Transportation Science and Engineering, Harbin Institute of Technology, Harbin 150090, China \\ ${ }^{2}$ School of Built Environment, The Copperbelt University, Kitwe 10101, Zambia \\ Correspondence should be addressed to Liping Cao; caoliping79@163.com
}

Received 27 January 2020; Revised 18 July 2020; Accepted 20 August 2020; Published 30 September 2020

Academic Editor: Farhad Aslani

Copyright (c) 2020 Nonde Lushinga et al. This is an open access article distributed under the Creative Commons Attribution License, which permits unrestricted use, distribution, and reproduction in any medium, provided the original work is properly cited.

This research was conducted to elucidate better understanding of the performance of crumb rubber asphalt modified with silicone-based warm mix additives. Two different silicone-based warm mix asphalt (WMA) additives (herein Tego XP and Addibit) were used to prepare crumb rubber modified (CRM) warm mix asphalt binders. The viscosity of these CRM binders was measured at different temperatures and shearing rates. Furthermore, softening point and penetration tests, Multiple Stress Creep Recovery (MSCR), Time Sweep (TS), Atomic Force Microscopy (AFM), Frequency sweep (FS), and Fourier Transform Infrared (FTIR) tests were also conducted on prepared samples. Based on these robust and rigorous laboratory experiments, it was established that viscosity of CRM binders was reduced by addition of Tego XP and Addibit WMA additives. However, WMA additives had different influence on rheological properties of the binder. CRM binder with Tego XP improved resistance to rutting of the binders but would degrade the fatigue performance. On the contrary, viscoelastic continuum damage (VECD) model results and those of phase angle approach revealed that the binder with Addibit improved resistance to fatigue cracking of the binders but had no adverse effects on high temperature rutting performance. FTIR test results established a presence of polydimethylsiloxane (PDMS) in CRM binders with Tego XP and Addibit. PDMS is a well-known hydrophobic organic and inorganic polymer that is water repellent; therefore, binders containing these silicone-based warm mix additives could be beneficial in resisting moisture damage in asphalt binders and mixtures. Morphology of CRM binders with and without WMA revealed good distribution of the rubber particles in asphalt binder matrix. Further addition of WMA increased surface roughness of the binder, which can be correlated to changes in microstructure properties of the binder. Therefore, the study concluded that addition of Tego XP and Addibit reduces viscosity and improves mechanical properties of the asphalt binder.

\section{Introduction}

1.1. Background. In light of the growing concern for global warming and increase in environmental emissions, the asphalt industry has been making frantic efforts to reduce its greenhouse emissions from asphalt without significantly affecting its mechanical properties $[1,2]$.

Crumb rubber (CR), a waste material manufactured by grinding waste vehicular tires, is one of the modifier of asphalt. This material has been widely used in asphalt mixture production due to immense benefits which include reducing the need for the disposal of waste tires and saving on raw materials and cost [3]. Rubberized asphalt concrete generally improve durability, reduce aging and oxidation, and enhance resistance to fatigue cracking, rutting, and reflective cracking. Furthermore, CRM asphalt binders lower costs of maintenance, noise generation, and improve skid resistance [4-10]. Despite these benefits, there are concerns in the application of CR in asphalt. These concerns include poor mixability, pumpability, workability and also the need for more heat energy when preparing such mixtures [11]. The production of rubberized asphalt concrete requires temperature of atleast $180^{\circ} \mathrm{C}[12-16]$ to obtain the required binder workability. The high temperature increases greenhouse gas emissions and the production of fumes, odor, and volatile organic compounds (VOCs) 
such as benzene, toluene, ethylbenzene, xylenes, and sulfur compounds [17].

In view of the emission concerns of rubberized asphalt mixes, warm mix asphalt (WMA) technologies can effectively lower the energy consumption and emissions from asphalt concrete [18]. In the recent past, researchers have investigated the application of WMA as a way to lower the production and lay down paving temperatures of asphalt concrete mixes. WMA is manufactured at temperatures of between $100^{\circ} \mathrm{C}$ and $140^{\circ} \mathrm{C}$ compared to hot-mix asphalt mixes which are produced at temperatures of about $150^{\circ} \mathrm{C}$ [19-22]. There are three methods or approaches for reducing the production and lay down paving temperatures of WMA. These approaches include the foaming approach, use of water-bearing agents, and the application of special additives for asphalt. For the foaming approach, small steam bubbles are produced in the binder. These bubbles increase the volume of the asphalt binder, thereby giving rise to improved binder wettability and reduced viscosity [23]. When water-bearing agents are used, chemically bound water is released from the agents into the asphalt during production. The released water results in the formation of steam which is finely dispersed in the asphalt mixture. These fine steam bubbles induce the formation of micropores that improve the volumetric properties and lay down compaction of binders [24]. Lastly, the addition of special additives which has paraffinic hydrocarbons as the main constituents results in in the reduction of viscosity of the binder. The paraffin component is typically soluble in asphalt when temperatures are between $80^{\circ} \mathrm{C}$ and $120^{\circ} \mathrm{C}$. However, the reduction of the binder viscosity is achieved when these paraffinic hydrocarbons dissolve in asphalt [25].

The application of warm-mix technology to CRM asphalt binders produce mixes with good engineering properties that could lower cost and environmental emissions. In spite of numerous previous studies on warm-mix asphalt, only a handful of researchers investigated rubberized asphalt in relation to warm mixes [26-28] and virtually no published literature exists on characterization of silicone-based WMA additives on properties of CRM asphalt binders. Therefore, this paper presents a study on performance variation of CRM asphalt binders due to addition of two silicone-based warm mix additives (namely, Tego XP and Tego Addibit) into asphalt.

Tego Addibit herein referred to as Addibit is a bitumen warm mix additive based on organo-modified siloxanes. It is utilized in foamed and nonfoamed bitumen production. Evonik Specialty Chemicals (Shanghai) Co. Ltd. manufactures Tego Addibit, and this additive possess antistripping and viscosity reduction component. The additives' main component is organic siloxane surfactant. The surface tension of the surfactant is lower than hydrocarbon surfactants and has excellent compatibility, strong thermal stability, and wettability among others. Unlike other commercial warm mix additives, siliconebased warm mix additives can also work without introducing water in asphalt mix. Therefore, water stability and reduced warm asphalt production can best be realized by using Addibit additive [29-31].
Tego XP is a new product based on organic-modified siloxane foam asphalt warm mix agent, manufactured by Evonik Specialty Chemicals (Shanghai) Co. Ltd, as an antistripping agent and suitable for stabilizing foam in the production process of foamed asphalt. Tego XP can also be used in the production nonfoaming asphalt. The silicone content of products is not more than $2 \%$. Tego XP additive can lower the production temperature of asphalt concrete mixes by $20^{\circ} \mathrm{C}-40^{\circ} \mathrm{C}$ and so reduce energy consumption and emission reduction in road paving. Tego XP has excellent thermal stability, which helps improve paving efficiency in areas with poor ventilation such as highway tunnels. One of the advantages of Tego XP is its application in heavy-duty asphalt such as Stone Mastic Asphalt (SMA) and Rubberized Asphalt (RA) pavements. Tego XP also possesses excellent foam stability effect. By reducing, the discharge temperature of asphalt mixture, Tego XP, reduces gas emissions in asphalt plants thereby improving the environmental friendliness of asphalt production and road paving [32].

1.2. Research Objectives and Scope. This study was conducted to elucidate better understanding of the variation in performance of CRM asphalt binders due to addition of two silicone-based WMA additives (namely, Tego XP and Tego Addibit). In particular, fatigue cracking, chemical functional groups, morphology, and rutting properties of rubberized WMA binders were investigated. To achieve the research purpose, the following specific objectives were formulated:

(i) To evaluate the effect of silicone-based WMA on conventional properties and viscosity of CRM binders

(ii) To evaluate the influence of WMA on high temperature rutting resistance and intermediate temperature fatigue cracking resistance of CRM asphalt binders employing MSCR and TS tests, respectively

(iii) To identify the chemical functional groups of CRM binders with and without WMA additives based on FTIR tests

(iv) To investigate the morphological changes and microstructure properties of CRM binders due to the addition of WMA additives employing AFM tests

\section{Experimental Methodologies}

2.1. Asphalt Binder and Additives. The asphalt binder utilized herein was PEN grade 60-80 asphalt (also known as 70\# base asphalt in China) which was sourced from local suppliers. The physical properties of the binder are given in Table 1. Basic properties of the crumb rubber modifier are given in Table 2. Pictorial images and properties of Tego Addibit and Tego XP WMA additives are shown in Figure 1 and Table 3, respectively. The crumb rubber modifier utilized herein was from one batch to ensure uniformity and quality control of samples. The modifiers and subsequent labels used herein are shown in Table 4. 
TABLE 1: Basic properties of penetration grade $70 \#$ base asphalt used herein.

\begin{tabular}{lcc}
\hline Test parameters & Specification & Test results \\
\hline Penetration $\left(25^{\circ} \mathrm{C}, 100 \mathrm{~g}, 5 \mathrm{~s}\right)(0.1 \mathrm{~mm})$ & $60-80$ & 68.9 \\
Ductility $\left(5 \mathrm{~cm} / \mathrm{min}, 15^{\circ} \mathrm{C}\right)$ & $\geq 40$ & 67 \\
Softening point $\left({ }^{\circ} \mathrm{C}\right)$ & $\geq 46$ & 46.3 \\
Flash point $\left({ }^{\circ} \mathrm{C}\right)$ & $\geq 230$ & 262 \\
Density $\left(\mathrm{g} / \mathrm{cm}^{3}\right)$ & - & 1.03 \\
Solubility in trichloroethylene $(\%)$ & $\geq 99.5$ & 99.8 \\
RTFOT mass change $(\%)$ & $\leq 0.8$ & 0.3 \\
Retained penetration $(\%)$ & $\geq 58$ & 78 \\
Ductility $\left(15^{\circ} \mathrm{C}\right)(\mathrm{cm})$ & $\geq 15$ & 44 \\
\hline
\end{tabular}

TABle 2: Basic properties of crumb rubber modifier used herein [31].

\begin{tabular}{lcc}
\hline Properties & Requirements & Test results \\
\hline Density $\left(\mathrm{g} / \mathrm{cm}^{3}\right)$ & $1.10-1.30$ & 1.18 \\
Ash content $(\%)$ & $\leq 8$ & 4.2 \\
Moisture content (\%) & $\leq 1$ & 0.4 \\
Metal content (\%) & $<0.05$ & 0.03 \\
Content of rubber hydrocarbon (\%) & $\geq 42$ & 48.0 \\
Content of carbon black (\%) & $\geq 28$ & 30 \\
Acetone extracts (\%) & $\leq 22$ & 8 \\
\hline
\end{tabular}

2.2. Production of Rubberized Warm Mix Asphalt Binders. Typically, CRM warm mix asphalt is prepared by mixing asphalt binder with crumb rubber at high temperature for a specified time. An asphalt sample of $750 \mathrm{~g}$ was heated at $140^{\circ} \mathrm{C}$ in a high shear mixer. Tego XP $(0.6 \%$ weight of asphalt) was added to base asphalt and sheared with high shear mixer at $4000 \mathrm{rpm}$ for 15 minutes. Exactly $18 \%$ of CRM was added to base asphalt at $170^{\circ} \mathrm{C}-176^{\circ} \mathrm{C}$ and shearing at $900 \mathrm{rpm}$ for 15 minutes. Finally, the temperature was increased to $180^{\circ} \mathrm{C}-185^{\circ} \mathrm{C}$ and shearing at $4000 \mathrm{rpm}$ for 30 minutes. This process is illustrated in Figure 2. The experiment was repeated for Tego Addibit additive (2\% weight of asphalt). For the preparation of CRM control asphalt binder the procedure was the same as the preparation technique of warm mix asphalt except no WMA additive was added to base asphalt. Herein base asphalt was heated to $160^{\circ} \mathrm{C}$ before adding crumb rubber modifier. Thereafter the procedure was as described above.

As shown in Figure 2, the interaction stages of bitumenrubber and warm mix asphalt have been presented in three steps as follows:

Stage 0 (asphalt/WMA blending): warm mix asphalt is blended with asphalt.

Stage I (CR modification and swelling phase): CR is added to prepared warm mix asphalt binder. Then, rubber particles begin to swell by absorbing the lighter components of asphalt and a gel-like layer is formed at the interface between rubber and asphalt.
Stage II (CR modification and shear grinding): at this phase rubber particles continue to swell and degradation begins. The polymer chains and network of crosslinks begin to break up under the action of shear grinding splitting the swollen rubber into small particles.

Stage III: development herein refers to degradation and completion of dissolution. The rubber particle degradation progresses until it fully dissolves in asphalt to obtain a homogenous binder.

It is important to note that rubber network degradation could enhance the absorption of lighter fractions from asphalt binder, when the rubber swells. The development of CRM binder properties is mainly controlled by the rubberasphalt interaction and has a significant effect on asphalt binder's storage stability. During the asphalt-rubber interaction, two phases occur: rubber particle swelling and rubber degradation [33-35].

2.2.1. Rubber Swelling. Due to absorption of solvents, the network in polymers experience volume expansion also called rubber swelling (Figure 3). Polymers that are not crosslinked easily swell in solvents such as asphalt binder and dissolves in a process called polymer dissolution. This dissolution of uncrosslinked polymers into the solvent (asphalt) generally involves two phenomena namely: disentanglement of the chain and solvent diffusion-induced swelling [37]. For polymer that have been crosslinked, the links between segments are established due to the limitations of the polymer network, whereas the network might swell by absorbing solvents but the dissolution would not occur. Polymers with network structures have limited swelling [38]. It is worth noting that waste tire rubber has the largest proportion of crosslinked/vulcanized polymer and a relatively small proportion of uncrosslinked polymer. Therefore, partial dissolution process is recorded due to limited polymer swelling of waste rubber particles in organic solvents $[39,40]$. The extent of swelling and rubber dissolution rate varies depending on compatibility levels between rubber and solvents. When rubber ixes with asphalt at elevated temperatures, the lighter components of asphalt diffuse into the network of rubber particles and induce swelling. The changes in volume of rubber particles and the subsequent formation of gel-like layer on the interface between asphalt and rubber decreases the distance between particles and consequently changes the fraction of the asphalt remaining, thereby making it stiff.

2.2.2. Chemical Degradation. Under long mixing times and elevated temperatures, chemical degradation of rubber network occurs. The network structure of the polymer formed by crosslinking prevents dissolution of the rubber network, and high shear and thermal energy induced in the mixing process destroys the rubber network crosslinks [41]. This process of degradation is also called depolymerisation 


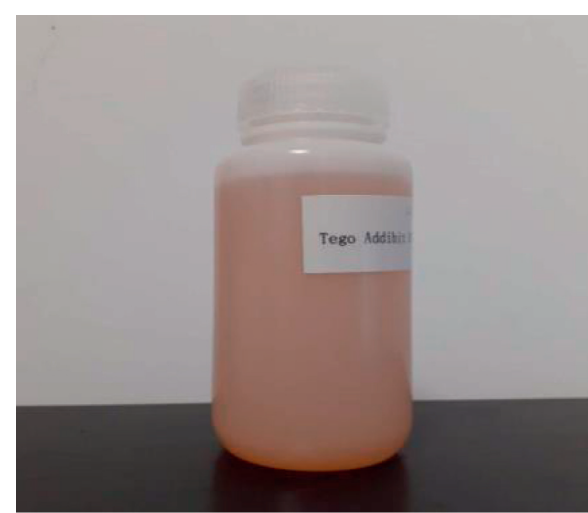

(a)

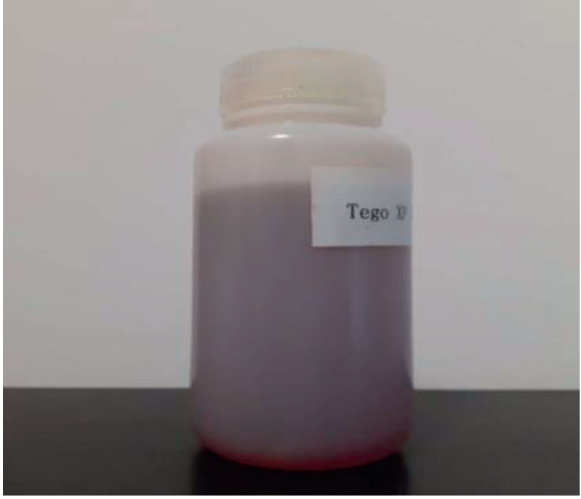

(b)

FIgUre 1: Silicone warm mix additives (a) Tego Addibit and (b) Tego XP.

TABLE 3: Basic properties of silicone warm mix additives.

\begin{tabular}{lccc}
\hline Properties of Tego Addibit & Values & Properties of Tego XP & Values \\
\hline Appearance & Clear, yellow & Appearance & Amber clear, liquid \\
Active content $(\%)$ & 40 & Acid value $(\mathrm{mg} \mathrm{KOH} / \mathrm{g})$ & $10-25$ \\
Density $\left(\mathrm{g} / \mathrm{cm}^{3}\right)$ & 0.9 & Water content $(\%)$ & $\leq 2$ \\
Viscosity at $25^{\circ} \mathrm{C}(\mathrm{mPa} . \mathrm{s})$ & 130 & Density $(\mathrm{g} / \mathrm{ml})$ & $0.85-0.95$ \\
Flash point $\left({ }^{\circ} \mathrm{C}\right)$ & $>100$ & $1 \% \mathrm{PH}$ value & $8.6-9.6$ \\
& & Viscosity mPa.s $\left(25^{\circ} \mathrm{C}\right)$ & $50-250$ \\
\hline
\end{tabular}

TABLE 4: Asphalt binder labels utilized herein.

\begin{tabular}{lcc}
\hline Asphalt binder & Modifier/additive & Label of samples \\
\hline Rubberized control binder & Crumb rubber (CR) & Control \\
Rubberized binder with Tego XP & CR + Tego XP & Tego XP \\
Rubberized binder with Tego Addibit & CR + Tego Addibit & Tego Addibit \\
\hline
\end{tabular}

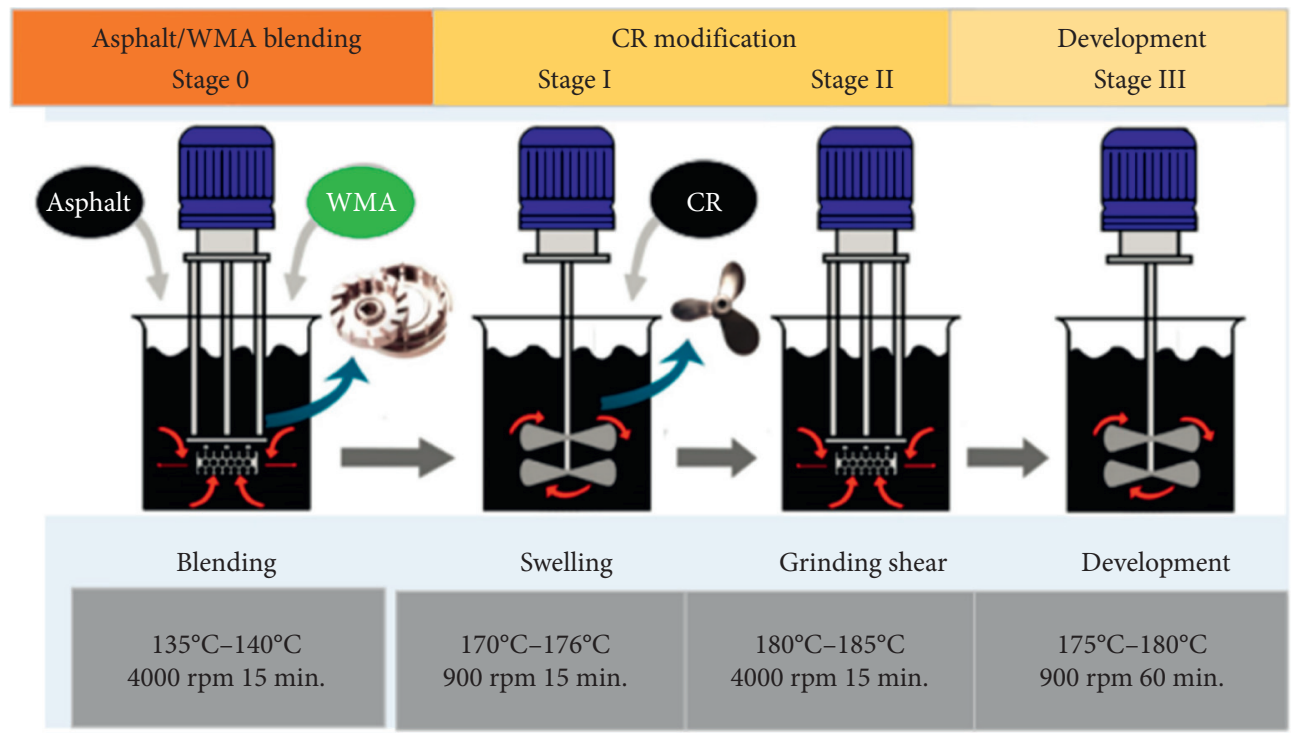

FIGURE 2: CRM warm mix asphalt modification procedure utilized herein. 


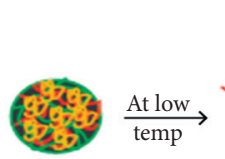

(a)

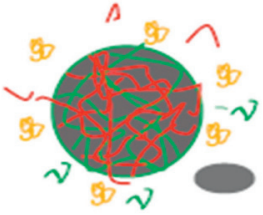

(b)

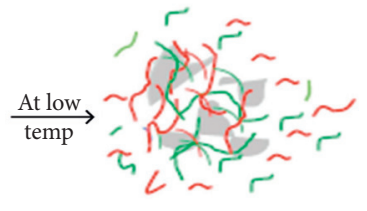

(c)

\section{$\sim$ Natural rubber \\ Synthetic rubber}

FIGURE 3: CR swelling and degradation in asphalt [36]. (a) Crumb rubber (CR). (b) Swollen CR, discharging oil and fillers to asphalt. (c) Breaking of CR.

or devulcanisation [33]. The degradation of rubber network removes the limitations of the polymer chains. The free chains of rubber polymer finally dissolve into the asphalt binder. The mixing energy imposed by the high shear mixer during rubber-asphalt interaction increase the rubber particles swelling process and improve the effects of size reduction. The rubber network degradation has a negative effect on development of mechanical properties of the binders $[42,43]$. However, it may be beneficial to improving the binder's storage stability [44].

\subsection{Asphalt Binder Testing and Parametric Measurements.} In this research, several laboratory experiments were performed on prepared CRM control asphalt binders and those modified with Tego XP and Tego Addibit warm mix additives, respectively. Figure 4 shows flowchart of experimental design procedures utilized in this research.

2.3.1. Viscosity Test. Viscosity of asphalt is a measure of resistance to flow of binders and/or mixes at mixing or laydown temperature. In this research, the Anton Paar Dynamic Shear Rheometer (DSR) MC-302 was utilized. The measuring technique is described elsewhere [45]. In the laboratory mixers or in plant mixing process, the asphalt binders exhibit a tendency for turbulent shear mixing at elevated shearing rates [46]. The version 1.17 of RheoCompass software was utilized to calculate results based on shear rate of 5 to $1000(1 / \mathrm{s})$, and hence viscosity was recorded.

\subsubsection{Conventional Binder Tests}

(1) Penetration Tests. Penetration is an index for consistency of binder at intermediate temperature. This test was conducted in conformity with ASTM D5. This test utilizes a needle of known dimensions to penetrate asphalt binder samples under a $100 \mathrm{~g}$ constant load at $25^{\circ} \mathrm{C}$ for 5 seconds. Penetration value is taken to be the distance the needle sinks $(0.1 \mathrm{~mm})$.

(2) Softening Point. The temperature where a $3.5 \mathrm{~g}$ weight of steel ball can no longer be supported bitumen or asphalt binder is known as the softening point. Prepared asphalt binder was poured into brass rings, and tested according to ASTM D36. Blends prepared with high softening point asphalt binders increased resistance to rutting. The softening point of rubberized control binders and those containing Tego XP and Tego Addibit were tested to understand the effects of the WMA additives on binder's softening characteristics.

2.3.3. Frequency Sweep Test. The DSR laboratory test was carried out using DHR-2 Rheometer TA instruments sourced from New Castle, Delaware, USA. High temperature from $50^{\circ} \mathrm{C}$ to $75^{\circ} \mathrm{C}$ and $0.1 \mathrm{~Hz}$ to $50 \mathrm{~Hz}$ frequency was used with a $25 \mathrm{~mm}$ diameter plate and a $1 \mathrm{~mm}$ hole setting out. Under conditions of controlled stress, the viscoelastic parameters of phase angle $(\delta)$ and complex modulus $\left(\mathrm{G}^{*}\right)$ were obtained. The desired $10 \mathrm{rad} / \mathrm{sec}$ oscillation rate could simulate the shear motion similar to a vehicular speed of 56 miles per hour $(90 \mathrm{~km} / \mathrm{h})$.

2.3.4. MSCR Test. The resistance to rutting of rubberized binders was evaluated based on the MSCR test. In this experimental test, binder samples were subjected to the repeated loading for a duration of 1 second followed by 9 seconds of recovery period. This loading and unloading pattern simulates the moving traffic condition of the actual pavement. The test is generally performed at $3.2 \mathrm{kPa}$ and $0.1 \mathrm{kPa}$ levels of stress and each contains 10 cycles according to the specification requirement of ASTM D7405. The rutting resistance performance is believed to be governed by $J_{n r}$ value, i.e., nonrecoverable creep compliance at $3.2 \mathrm{kPa}$. MSCR test was conducted using DSR at optimal temperature of $64^{\circ} \mathrm{C}$ on TFOT aged samples, in which a TA manufactured Instruments DHR-2 Rheometer from New Castle (Delaware, USA) was employed.

2.3.5. Time Sweep Test. Time sweep test was conducted using DHR-2 Rheometer from New Castle (Delaware, USA). The $8 \mathrm{~mm}$ diameter parallel plate spindle and a $2 \mathrm{~mm}$ gap were used at a frequency of $20 \mathrm{~Hz}$ and a temperature of $20^{\circ} \mathrm{C}$. The samples were conditioned for 10 minutes to attain the required thermal equilibrium for the test. Prior to $90 \%$ decrease of the complex shear modulus from initial values, the binder is believed to be in the linear viscoelastic state. The stress level of $100 \mathrm{kPa}$ was applied to obtain the fatigue damage curve. Two replicates were used to verify the repeatability and a third one would have conducted, had the difference in results of the replicates exceeded $10 \%$. The time sweep test was not terminated until the complex modulus decreased to less than $100 \mathrm{kPa}$ to ensure as much data as possible was captured.

2.3.6. Fourier Transform Infrared-FTIR. The intensity of FTIR spectra from absorption peaks was utilized to identify the chemical functional groups of polymer additives in asphalt. In this research, the polymer additive was a composite blend of crumb rubber and silicone-based warm mix additives in asphalt. This was achieved by the utilization of the Thermo Scientific Nicolet iS 50 instrument, manufactured by Thermo Fisher Scientific in Massachusetts, USA. 


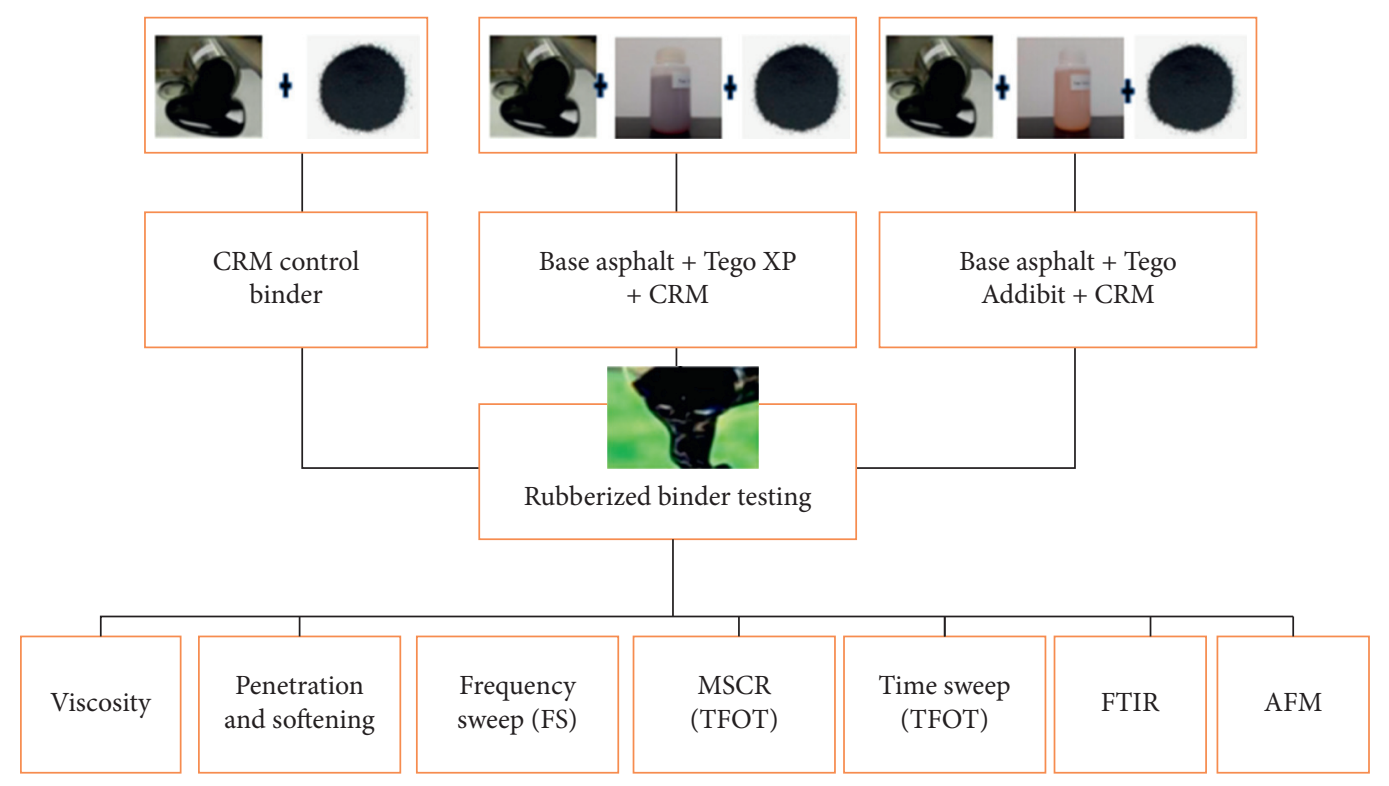

FIGURE 4: Experimental design flowchart of procedures utilized herein.

The preparation of samples involved heating to $150{ }^{\circ} \mathrm{C}$ to make a better flow, and thereafter placing them on the slide moulds surface. The test procedure was conducted under the wavenumbers from $4000 \mathrm{~cm}^{-1}$ to $500 \mathrm{~cm}^{-1}$ with the scan frequency of 32 times/min.

2.3.7. Atomic Force Microscopy (AFM). The morphological analysis of CRM asphalt binders with and without Tego Addibit and Tego XP were further conducted to obtain the surface roughness based on AFM test. The heat-casting method was used in the preparation of asphalt samples. In this method, asphalt binders were heated to flow at $150{ }^{\circ} \mathrm{C}$ and then poured onto the microscope glass slide moulds to form thin layer films. Herein, Dimension Fast Scan from Bruker (Bruker Corporation, Billerica, Massachusetts, USA) was utilized, whose user guide was also followed to conduct AFM analysis.

\section{Analysis of Results and Discussion}

3.1. Conventional Properties. The penetration test at $25^{\circ} \mathrm{C}$ generally gives the consistency of asphalt binders near average yearly service temperature; thus, it has some influence on the overall performance of asphalt pavements. The penetration test results for all three binders are shown in Figure 5(a). For CRM binders with Tego XP additive, the penetration value decreased by $7 \%$ which means asphalt binder hardened. However, for CRM with Addibit additive, the penetration values increased compared to CRM control binders by $6 \%$, which means asphalt binder softened.

Softening point is an important indicator used in characterizing performance of asphalt binders at high temperature. It is basically the temperature at which asphalt binders change to viscous flow. High softening point corresponds to improved high temperature performance [46]. From Figure 5(a), it can be seen that addition of Tego XP and
Addibit to CRM binders increased the softening point by $6 \%$ and $2 \%$, respectively, as compared to CRM control binders.

The change in temperature susceptibility of the binders was investigated by calculating the penetration index (PI). Using the penetration values at $25^{\circ} \mathrm{C}$ and softening point results and an assumption that penetration of an asphalt binder at its softening point is 800, PI was calculated according to the following equation [46]:

$$
\begin{aligned}
& \mathrm{PI}=\frac{(20-500 A)}{(1+50 A)}, \\
& A=\frac{\left(\log 800-\log P_{25}\right)}{\left(T_{\mathrm{SP}}-25\right)},
\end{aligned}
$$

Where A is temperaturesusceptibility of bitumen and PI is penetration index, P25 is penetration index at $25^{\circ} \mathrm{C}$ and Tsp is the softening point of bitumen. Results in Figure 5(b) show that PI values for CRM control asphalt binders, Tego $\mathrm{XP}$, and Addibit samples were 0.91, 1.48, and 1.21, respectively. The higher the PI value of the asphalt binder, the lower is its temperature susceptibility. Therefore, this result suggests that CRM binders with Tego XP have lower temperature susceptibility.

3.2. Analysis of Viscosity Test Results. The viscosity is used to determine the flow characteristics of the binder which determine the ability of the binder to be mixed and compacted and is also known as workability. Higher mixing and compaction temperatures are required for higher viscosity value results, which may increase energy consumption. Diab [47] demonstrated that the viscosity of polymer-modified asphalt binders is dependent on the shearing rate and the dosage of the additive. The shape of the viscosity curve of any fluid can be revealed by testing the sample at a wide range of shearing rates [47]. Anton Paar Rotational Rheometer was used to measure the experimental values of the viscosities at 


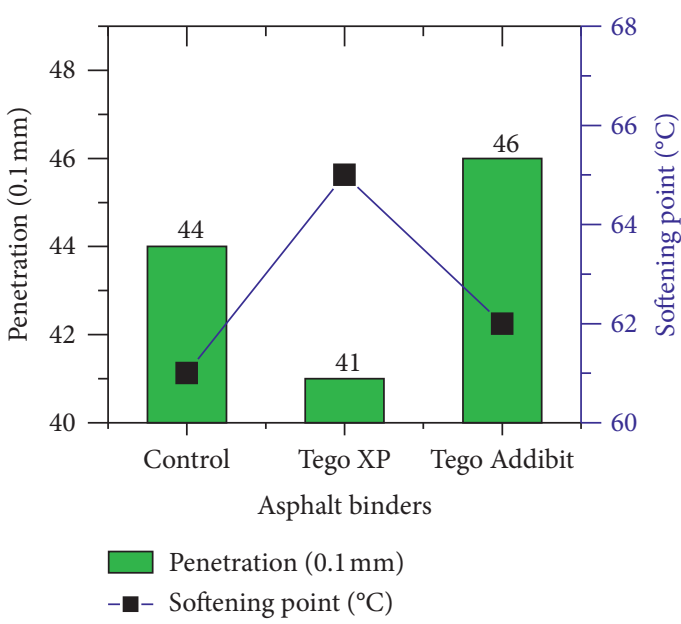

(a)

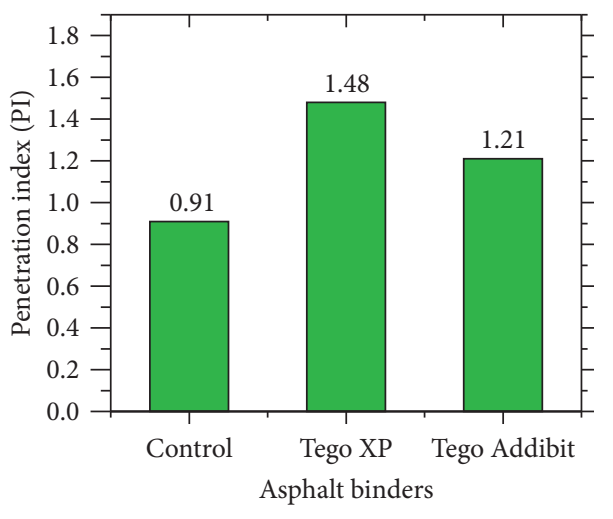

(b)

FIgURE 5: Conventional tests: (a) penetration at $25^{\circ} \mathrm{C}$ and softening point test and (b) penetration index (PI) of rubberized binders.

shear rates ranging from 5 to $1000(1 / \mathrm{s})$ and temperature ranging from $135^{\circ} \mathrm{C}$ to $185^{\circ} \mathrm{C}$.

Figures 6(a)-6(c) present the viscosity-shear rate plots for the CRM asphalt binders (with and without WMA). These results clearly demonstrated that viscosity is dependent on the shear rate. Viscosity decreased with increase in the shear rate. Binder viscosity was reduced by addition of Tego XP and Addibit additives. For the CRM binders with Tego XP, the viscosity rate of reduction was $8 \%$, whereas for binders with Addibit additives, the viscosity reduction was $16 \%$, This result demonstrated that Addibit additive is able to reduce the viscosity of the CRM binder. Relatively, lower gain in shear susceptibility with corresponding increase in viscosity has been reported to be associated with better pavement performance. Clearly, the increase in the temperature results in an obvious decrease in the viscosity. Figure 6(b) presents viscosity-temperature results. All the three binders met the Superpave viscosity specification limits of less than $3.0 \mathrm{~Pa} . \mathrm{s}$ at $135^{\circ} \mathrm{C}$.

\subsection{High Temperature Performance of Asphalt Binders}

3.3.1. Analysis of Complex Modulus and Phase Angle Results. The complex shear modulus $\left(G^{*}\right)$ can be considered the sample's total resistance to deformation when repeatedly sheared, while the phase angle $(\delta)$ is the lag between the applied shear stress and the resulting shear strain. The larger the phase angle $(\delta)$, the more viscous the material. Asphalt binders are viscoelastic materials that exhibit both elastic solid and viscous liquid behavior. Elastic solids have deformation caused by loading which is recoverable after load removal. However, viscous liquid indicates that deformation caused by loading is not recoverable even after load removal [48]. This is because, for viscous liquid, as long as stress is applied, the strains linearly increase without bound. Nevertheless, after load removal, no stress remains available to move the piston back through fluid; hence, the strains are permanent. The Christensen Anderson Marasteanu (CAM) model as well as the Williams-Landel-Ferry (WLF) shift factors represented by equations (3) and (4) were utilized to develop master curves [31]:

$$
\begin{aligned}
G^{*} & =G_{e}^{*}+\frac{G_{g}^{*}-G_{e}^{*}}{\left[1+\left(f_{c} / f^{\prime}\right)^{k}\right]^{m_{c} / k},} \\
\log \alpha_{T} & =-\frac{C_{1}\left(T-T_{\text {ref }}\right)}{C_{2}+\left(T-T_{\text {ref }}\right)},
\end{aligned}
$$

where $G^{*}$ is complex modulus at reduced frequency $f^{\prime}$, while $G_{e}^{*}$ is equilibrium complex modulus when frequency is infinitely close to zero, often assumed 0 for asphalt binders. $G_{g}^{*}$ is complex modulus at glass transition when frequency is close to infinity. $k$ and $m_{c}$ are shape parameters. $\alpha_{T}$ are shift factors which can be obtained by fitting William-Landrel-Ferry (WLF) function. $T_{\text {ref }}$ is standard reference temperature, and $C_{1}$ and $C_{2}$ are the model parameters.

Before the master curves were constructed, the applicability of dataset from frequency sweep for shifting using the time temperature superposition principle (TTSP) was performed through constructing black diagrams. Figure 7(a) shows the black diagram for CRM asphalt binders with and without warm mix additives. It can be seen from the black diagrams that the binders tested resembled a single curve, which confirms the suitability of applying TTS principle for the range of temperature in question.

To be able to resist rutting, the asphalt binder ought to be stiff (so as not to deform extensively after load application) and ought to be elastic as well (so as to be able to return to the original shape after load application). In other words, the complex shear modulus elastic component $(\mathrm{G} * / \mathrm{Sin}(\delta))$ should be relatively large [48]. Further lower phase angle $(\delta)$ values correspond to the increased elastic component of $\mathrm{G}^{*}[8,48]$, which increase resistance to rutting. 


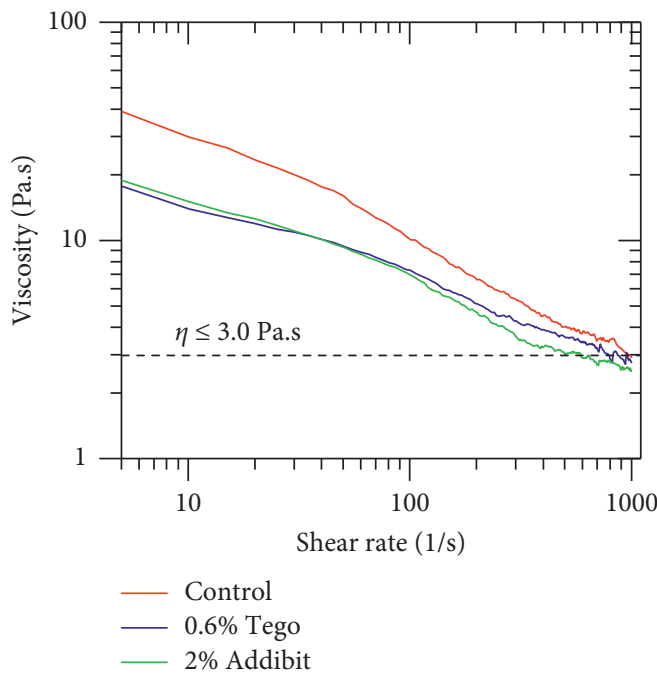

(a)

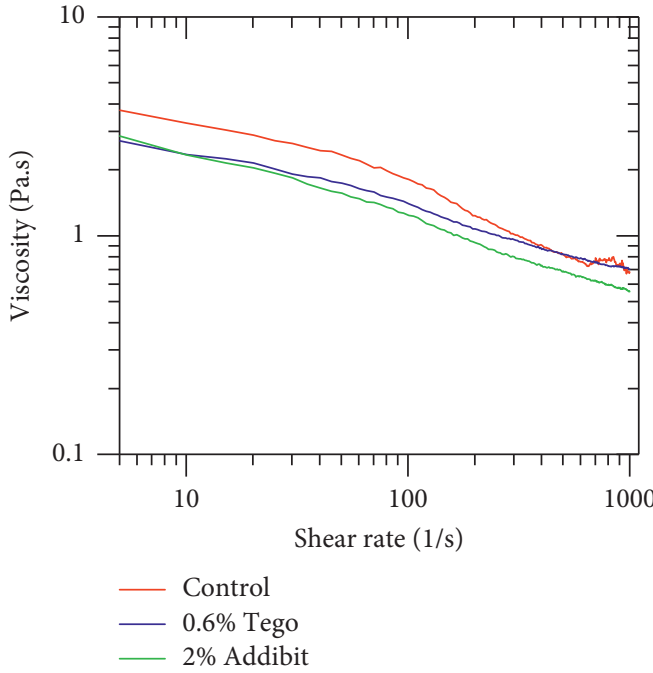

(c)

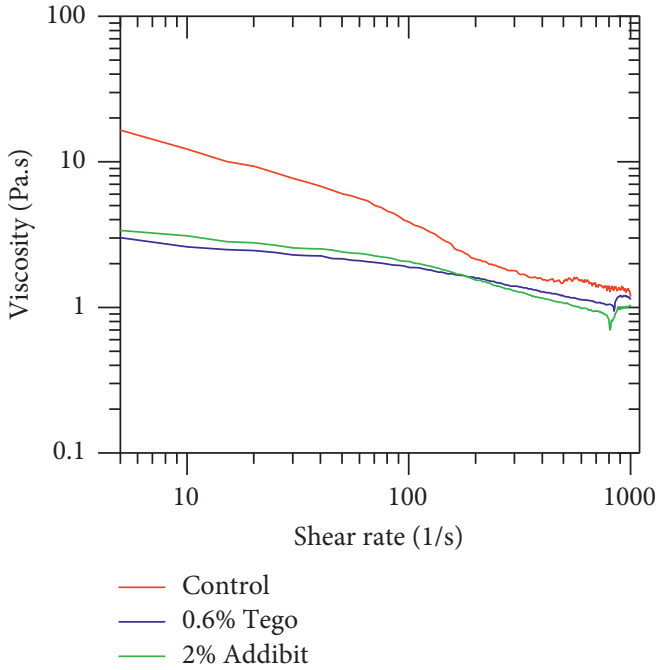

(b)

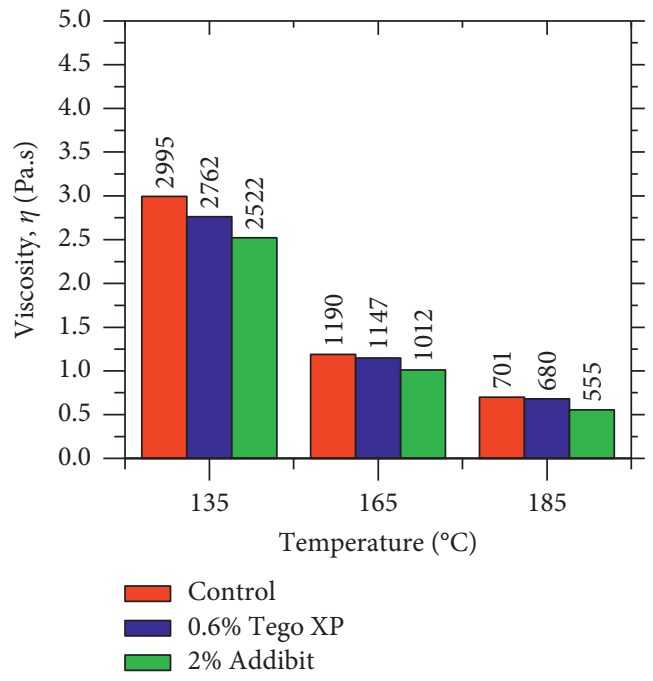

(d)

Figure 6: Viscosity and shear rate of CRM asphalt with and without WMA additives at (a) $135^{\circ} \mathrm{C}$, (b) $165^{\circ} \mathrm{C}$, and (c) $185^{\circ} \mathrm{C}$ and (d) viscositytemperature at 1000 shearing rate $(1 / \mathrm{s})$.

Figures 7(b) and 7(c) present master curve and phase angle, respectively, for CRM binders with and without warm mix additives at high temperature ranges of $50^{\circ} \mathrm{C}, 64^{\circ} \mathrm{C}$, and $75^{\circ} \mathrm{C}$. It was found addition of warm mix additives shifted the master curve to a lower $\mathrm{G}^{*}$ value in both high and low temperature regions. By comparing all the three binders, complex modulus $\left(\mathrm{G}^{*}\right)$ for the CRM control binders were higher than WMA binders in general but binders with Tego XP had overall better elastic component $\mathrm{G}^{*} / \operatorname{Sin}(\delta)$ and lower phase angle $(\delta)$ which was an indication of improved resistance to permanent deformation, as shown in Figures 7(c) and 7(d). In this paper, all binders were tested at the high-performance temperatures of $50^{\circ} \mathrm{C}$ to $75^{\circ} \mathrm{C}$ and thus could exhibit viscoelastic properties.

3.3.2. Permanent Deformation Based on MSCR Test. In an MSCR test, the nonrecoverable creep compliance $\left(J_{n r}\right)$ is determined to predict the permanent deformation potential of the binder. While percentage recovery can be used to predict the binder's ability to recovery from creep loading in a predetermined period of time and subsequent stress removal. In this research, equations (5)-(9) given by Behnood et al [49] were used to determine the $J_{n r}$ and percentage (\%) recovery as follows:

$$
\begin{aligned}
J_{n r_{0.1}} & =\frac{\sum_{N=11}^{20}\left[J_{n r}(0.1, N)\right]}{10}, \\
J_{n r_{3.2}} & =\frac{\sum_{N=1}^{10}\left[J_{n r}(3.2, N)\right]}{10}, \\
J_{n r_{\text {diff }}} & =\frac{\left[J_{n r_{3.2}}-J_{n r_{0.1}}\right]}{J_{n r_{0.1}}}
\end{aligned}
$$




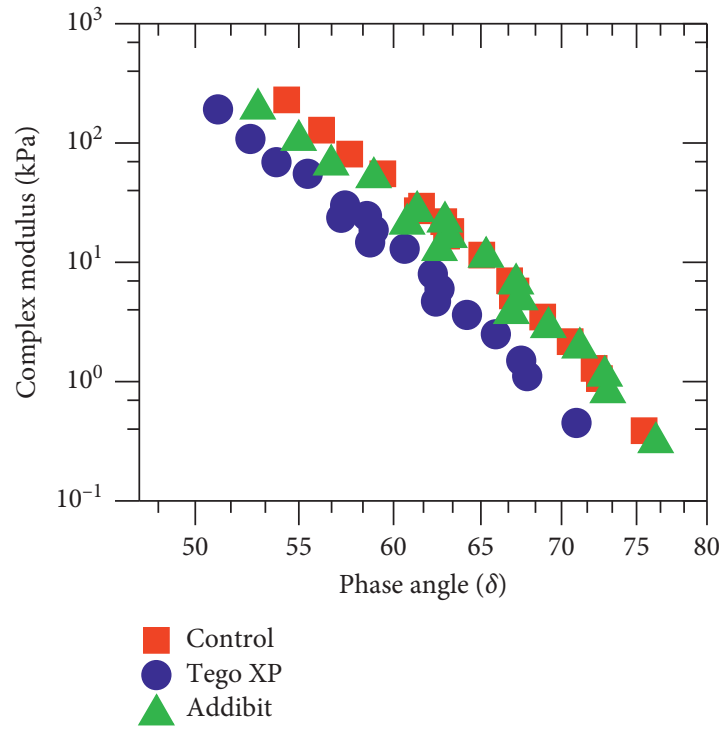

(a)

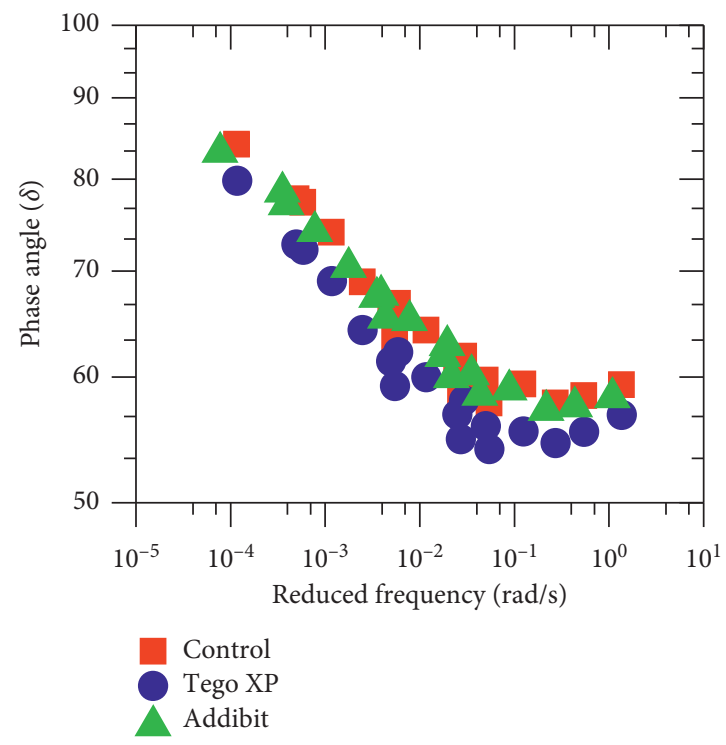

(c)

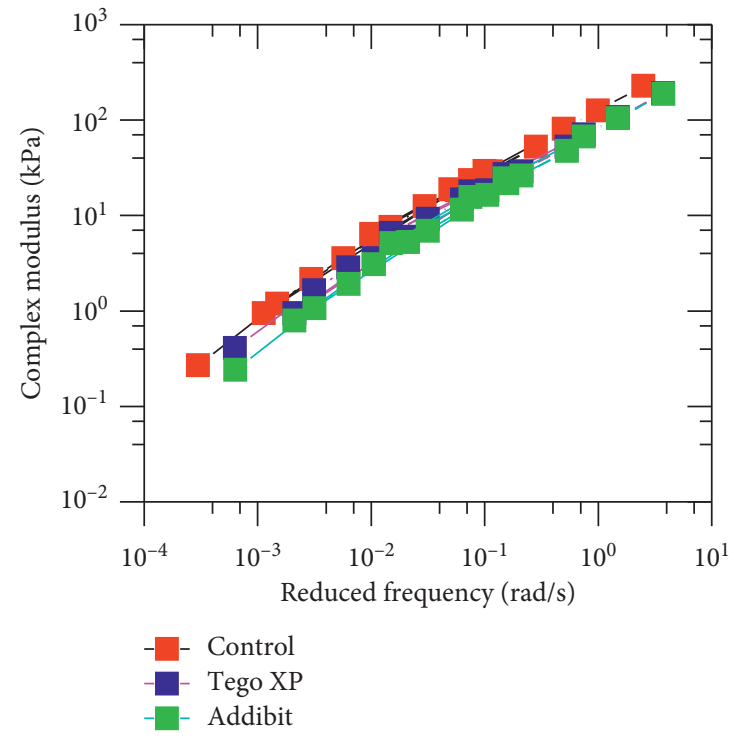

(b)

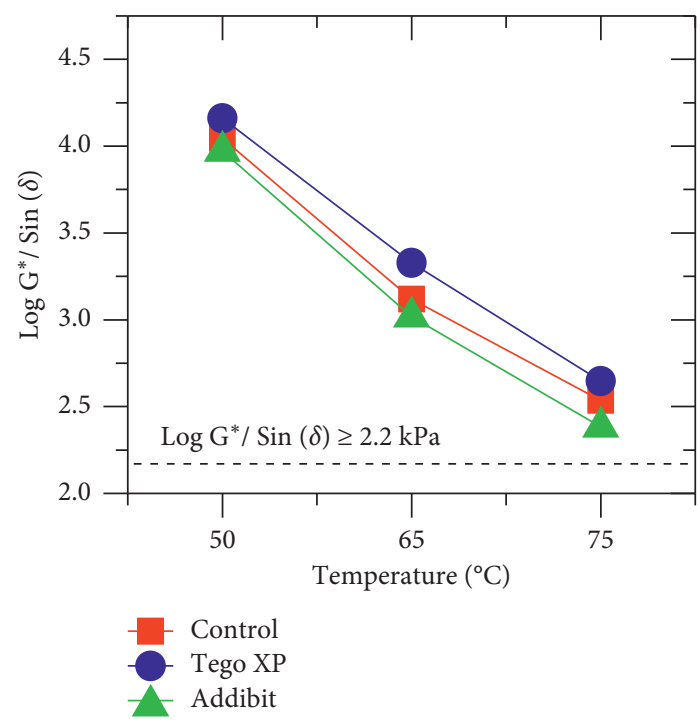

(d)

FIgURE 7: (a) Master curve, (b) phase Angle, (c) black diagram, and (d) Shenoy rutting parameter (0.1 Hz frequency) of CRM binders with and without WMA additives at high temperatures $50^{\circ} \mathrm{C}, 64^{\circ} \mathrm{C}$, and $75^{\circ} \mathrm{C}$.

$$
\begin{aligned}
& R_{0.1}=\frac{\sum_{N=11}^{20}\left[\epsilon_{r}(0.1, N)\right]}{10}, \\
& R_{3.2}=\frac{\sum_{N=1}^{10}\left[\epsilon_{r}(3.2, N)\right]}{10},
\end{aligned}
$$

where $\epsilon_{r}(3.2, N)$ and $\epsilon_{r}(0.1, N)$ are the $\%$ recovery at $3.2 \mathrm{kPa}$ and at $0.1 \mathrm{kPa}$ number of cycles $\mathrm{N}$, respectively, and $N$ is the number of cycle at each level of stress.

Results shown in Figure 8 revealed that rubberized binders containing Tego XP showed a greater resistance to permanent deformation irrespective of the stress level applied. From these results, it can be said that Tego XP warm mix additive is better in resisting the permanent deformation at service temperatures compared to control rubberized binders. The difference in creep compliance (Diff- $J_{n r}$ ) between $0.1 \mathrm{kPa}$ and $3.2 \mathrm{kPa}$ levels of stress for Control, Tego Addibit, and Addibit binders samples were $57.8 \%, 68.8 \%$, and $112 \%$, respectively. Diff- $J_{n r}$ for binders with Addibit was above the $75 \%$ specification limit. However, rubberized binders prepared with Tego XP and control binders were within the specification limits, as shown in Table 5. Overall, binders with Tego XP could support extremely heavy traffic compared to control binders, which could support very heavy traffic only. Furthermore, percentage recovery, although not included in specification limits, gave an indication of the binder's ability to recover after application and removal of loads. 


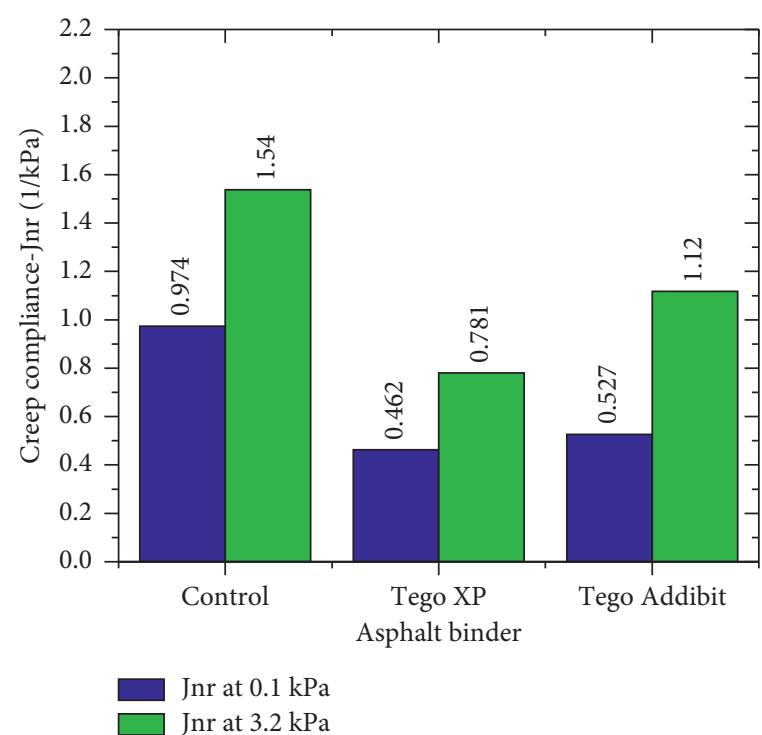

(a)

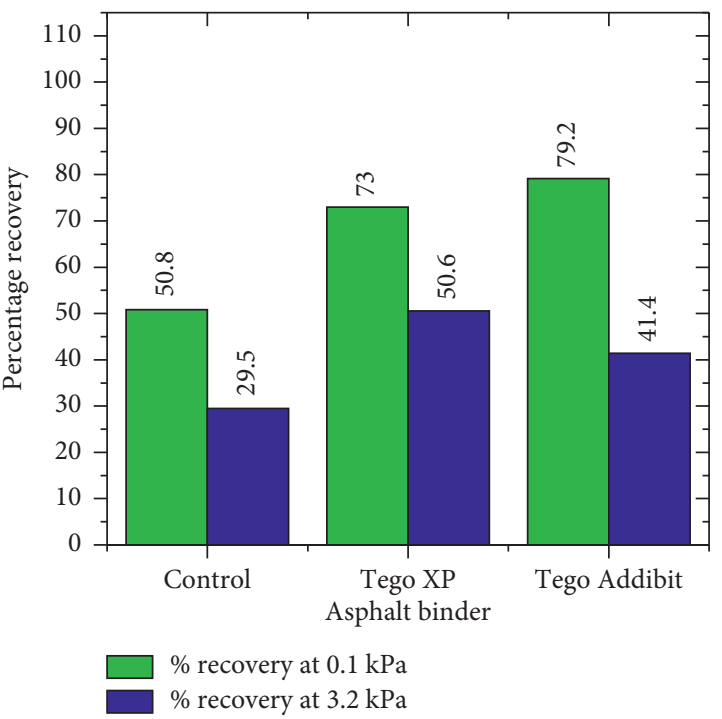

(b)

Figure 8: (a) Nonrecoverable creep compliance $\left(J_{n r}\right)$. (b) Percent recoverable silicone warm mix asphalt.

Table 5: Definition of traffic level on the MSCR parameters [20].

\begin{tabular}{lccc}
\hline Grade & Max. $J_{n r} 3.2(\mathrm{k} / \mathrm{Pa})$ & Max. $J_{n r}$ diff $(\%)$ & Traffic level \\
\hline $\mathrm{S}$ & $<4$ & 75 & Standard \\
$\mathrm{H}$ & $<2$ & 75 & Heavy \\
$\mathrm{V}$ & $<1$ & 75 & Very heavy \\
$\mathrm{E}$ & $<0.5$ & 75 & Extremely heavy \\
\hline
\end{tabular}

As $J_{n r}$ values decrease, the stiffer the asphalt becomes hence more rut resistant.

\subsection{Fatigue Cracking Resistance of Asphalt Binders}

3.4.1. Fatigue Modeling Based on Simplified Viscoelastic Continuum Damage (S-VECD) Theory. In order to investigate the fatigue cracking performance of asphalt binders, the time sweep test was conducted on thin film oven test (TFOT) aged asphalt binders. The S-VECD model was used to analyse time sweep (TS) test data. Details about the S-VECD model and the corresponding application of TS test data to characterize fatigue cracking of asphalt binder was performed according to Wang et al. [50]. Key aspects of this modeling approach are summarized as follows.

Damage evolution is based on Schapery's work potential theory [51]. In the work potential theory, the rate-dependent damage evolution rate is expressed as follows:

$$
\frac{d S}{d t}=\left(\frac{\partial W^{R}}{\partial S}\right)^{\alpha}
$$

where $S$ is the internal state variable representing damage; $W^{R}$ is the work performed; $\alpha$ is the undamaged materialdependent constant; and $t$ is time. In this study, $\alpha=1 / m$, where $m$ is the fitting slope parameter of the linear viscoelastic dynamic shear modulus $\left(\left|\mathrm{G}^{*}\right| \mathrm{LVE}\right)$ master curve. $W^{R}$ is quantified using PSE density:

$$
W^{R}=\frac{1}{2} C(S)\left(\gamma^{R}\right)^{2}
$$

where $C(S)$ is pseudostiffness and can be determined as follows:

$$
C(S)=\frac{\tau_{P}}{\gamma_{p}^{R} \times \mathrm{DMR}},
$$

where $\tau_{P}$ is the effective (measured) peak shear stress in a given cycle. $\mathrm{DMR}=$ dynamic modulus ratio $=\left|\mathrm{G}^{*}\right|$ fingerprint $/ \mathrm{G}^{*} \mid \mathrm{LVE}$. $\gamma_{p}^{R}$ is the peak pseudostrain for that given cycle, defined as follows:

$$
\gamma_{p}^{R}=\frac{1}{G_{R}} \gamma_{p i} \times\left|G^{*}\right|_{\mathrm{LVE}}
$$

where $\gamma_{p i}$ is the peak shear strain in the given cycle, $\left|G^{*}\right|_{\mathrm{LVE}}$ is the dynamic shear modulus for linear viscoelastic at a given loading frequency and temperature, and $G_{R}$ is the arbitrary reference modulus, assumed to be 1 . For DSR cyclic loading with zero mean displacement, equation (13) can be reduced to the following for cycle $i$ :

$$
\gamma_{p i}^{R}=\gamma_{p i} \times\left|G^{*}\right|_{\mathrm{LVE}}
$$

Equations (10)-(14) can be combined, and equation (10) is numerically integrated to solve for damage, $S$, as a function of time:

$$
S=\sum_{i=1}^{N}\left[\frac{\mathrm{DMR}}{2}\left(\gamma^{R}\right)^{2}\left(C_{j-1}-C_{j}\right)\right]^{(\alpha /(1+\alpha))},
$$



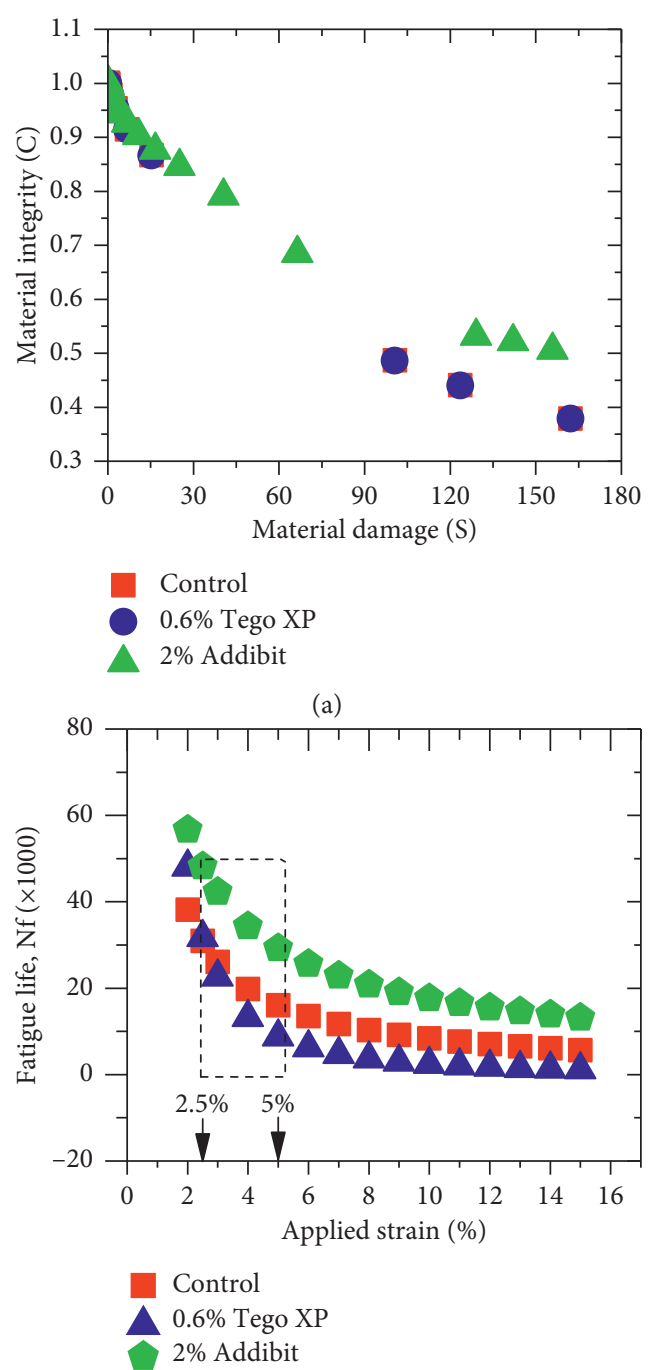

(b)

FIgURE 9: (a) VECD damage curve and (b) fatigue life ( $N f$ ) of CRM binders with and without WMA additives.

where $j$ is the time steps. The data from the fatigue test was used to calculate $C(S)$ and $S$, and the model was then fitted as follows:

$$
C=1-C_{1}(S)^{C_{2}},
$$

where the model parameters that best fit the data are $\mathrm{C} 1$ and C2. Combining equations (10), (11), (14), and (16) allows for model derivation between strain amplitude, $\gamma_{p}$, and loading cycles:

$$
N=\frac{f \cdot 2 \alpha \cdot S^{1-\alpha C_{2}+\alpha}}{\left(1-\alpha C_{2}+\alpha\right)\left(C_{1} C_{2}\right)^{\alpha}\left(\left|G^{*}\right|_{\mathrm{LVE}} \cdot \gamma_{p}\right)^{2^{\alpha}}}
$$

where $t$ is the loading time and $f$ is the loading frequency used in fatigue testing. If $S$ is set to $S$ at failure $\left(S_{f}\right)$, fatigue life can be determined using equation (17) in terms of the numbers of cycle to failure $(N f)$ at any strain amplitude.

Figure 9 shows the TS test results at two applied strains $(2.5 \%$ and $5 \%)$. Higher cycles to fatigue $(N f)$ refer to better resistance of fatigue cracking. According to Figure 9, the $N f$ values of CRM binders with Addibit was higher than control binder by $42 \%$, whereas $N f$ values for CRM binders with Tego XP was lower than the control binder by $46 \%$. The enhanced fatigue resistance of Addibit binders was attributed to the decrease in complex modulus of binders containing Addibit as can be seen in Figure 10.

3.4.2. Time Sweep (TS) Test Failure Definition. The number of loading cycles to failure has been defined as fatigue life, more especially in the strain-controlled mode. Several researchers used the peak in the phase angle approach to evaluate the fatigue life of asphalt binders, mastics, and mixtures [52, 53]. According to this approach, a point showing the maximum phase angle is a reasonable fatigue failure point, since the phase angle versus time curve shows a rapid loss of the phase angle when asphalt no longer accumulates distress. 


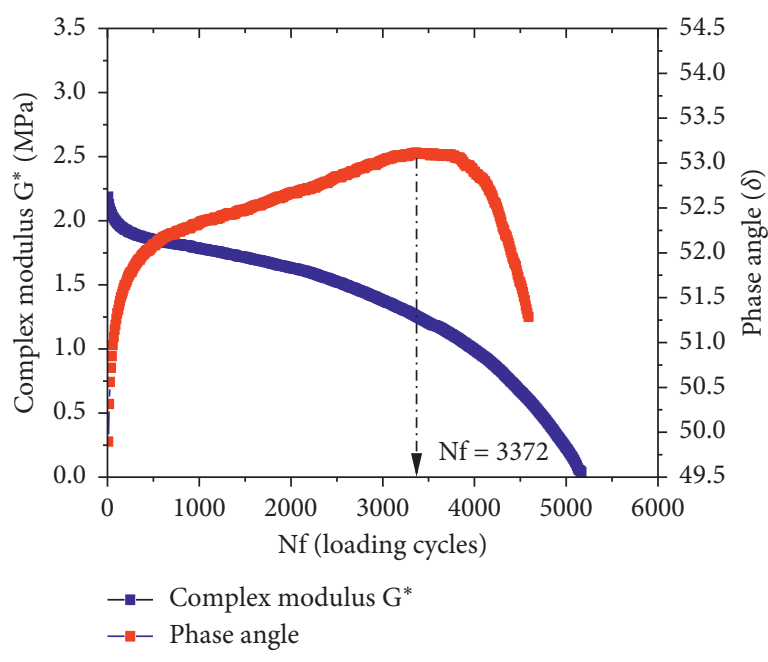

(a)

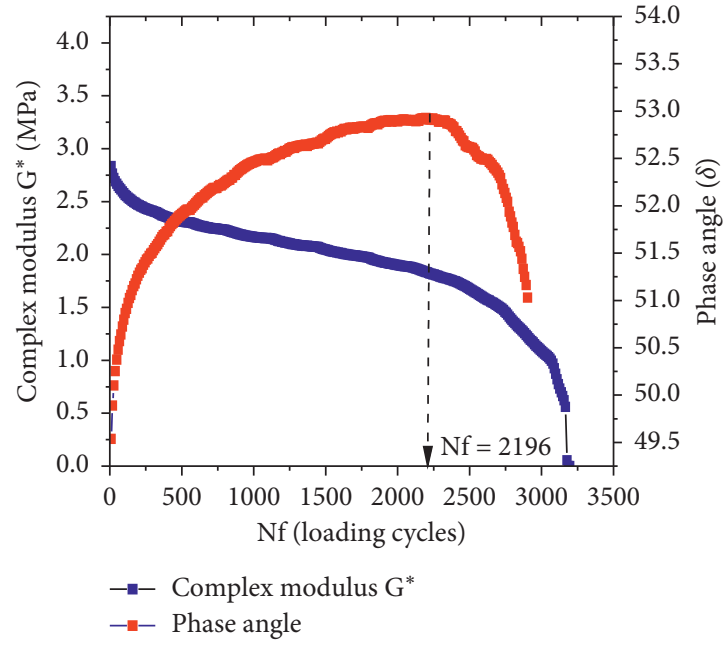

(b)

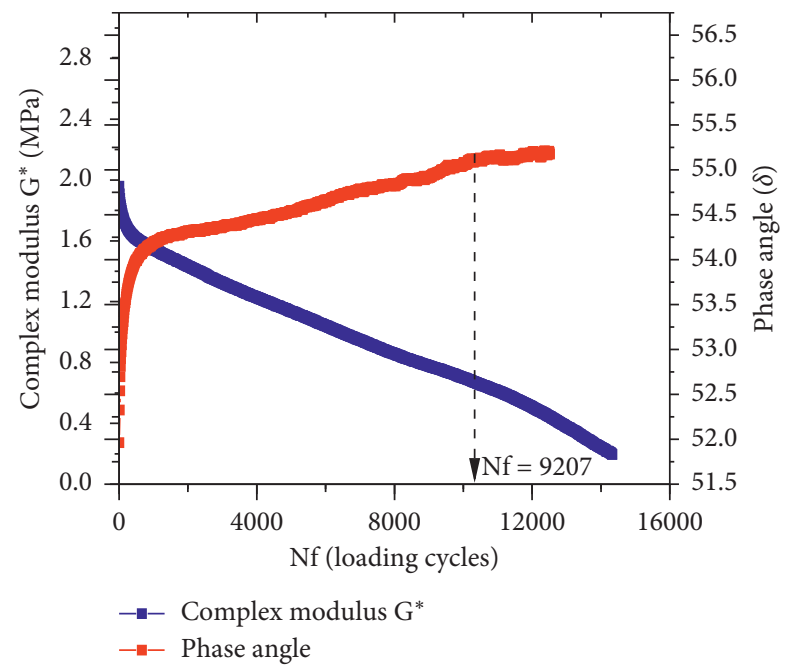

(c)

Figure 10: Complex modulus and phase angle results rubberized binders from time sweep test. (a) Control. (b) Tego XP. (c) Tego Addibit.

Figure 10 presents complex modulus and phase angle results from time sweep test. Using the peak in the phase angle approach to define the fatigue failure point, number of cycles before failure for Addibit binders was 9200 for $100 \mathrm{kPa}$ stress level applied, whereas control and binders with Tego were 3372 and 2196, respectively. The CRM binder containing Addibit was more resistant to fatigue cracking due to the softening of Addibit modified binders. This finding was in agreement with previous studies by Pouranian et al. [8], where WMA enhanced the rutting performance of CRM asphalt binders and had a slightly negative effect on fatigue cracking performance of CRM asphalt binders. Conversely, the reduced resistance of CRM binders containing Tego XP was attributed to increased binder stiffness or complex modulus as can be seen in Figure 10.

\subsection{Chemical and Morphological Analysis}

3.5.1. Analysis of FTIR Test Results. FTIR test was used to identify the functional groups of CRM asphalt with and without warm mix additives. The results shown in Figure 11 of an infrared (IR) spectrum revealed for CRM binders with and without Tego XP and Addibit. Absorption peaks $2921 \mathrm{~cm}^{-1}$ and $2850 \mathrm{~cm}^{-1}$ correspond to $\mathrm{CH} 2$ and - $\mathrm{CH} 3$ Stretching (Alkanes) of asphalt binder. Absorption peaks $1600 \mathrm{~cm}^{-1}$ represent $\mathrm{C}=\mathrm{C}$ stretching (Aromatics) and absorption peaks around $1460 \mathrm{~cm}$ 1 represent absorption peaksaround $1460 \mathrm{~cm}^{-1}$ represent $\mathrm{CH} 2$ bending (aliphatic group) and those around $1000-1100 \mathrm{~cm}^{-1}$ represent $\mathrm{Si}-\mathrm{O}-\mathrm{Si}$ bond vibrations and correspond to polydimethylsiloxane-PDMS [54]. The absorption peaks $722 \mathrm{~cm}^{-1}$ and $810 \mathrm{~cm}^{-1}$, in the infrared spectra, correspond to a benzene ring substitution area, as shown in Table 6. Peaks from Tego XP and Addibit disappeared in CRM binders, which indicated that the reaction was physical rather than chemical.

3.5.2. Homogeneity Based on AFM. The AFM test is capable of evaluating topography and phase image contrasts of polymer-modified binders [57]. Studies have shown that 


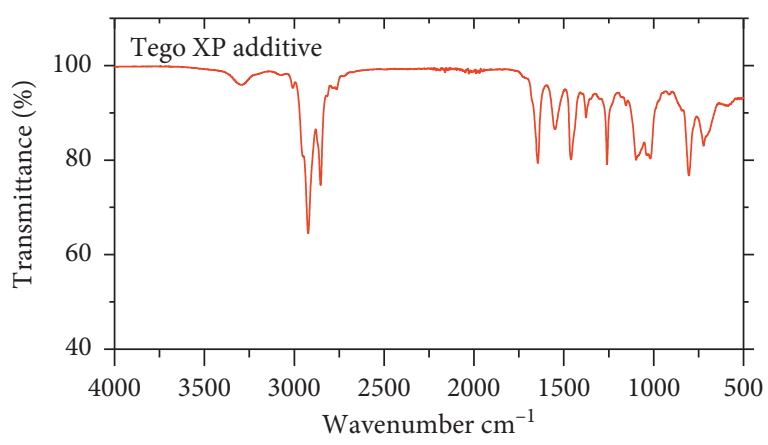

(a)

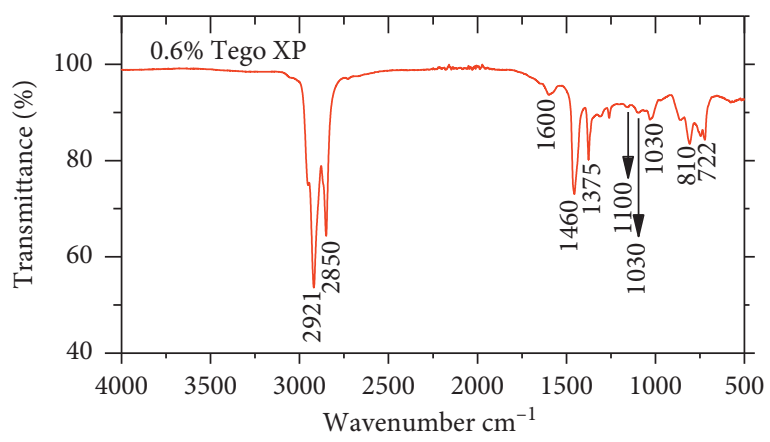

(c)

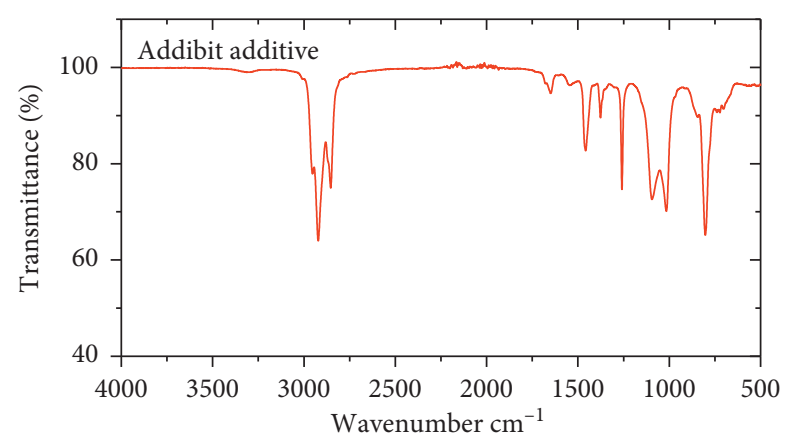

(b)

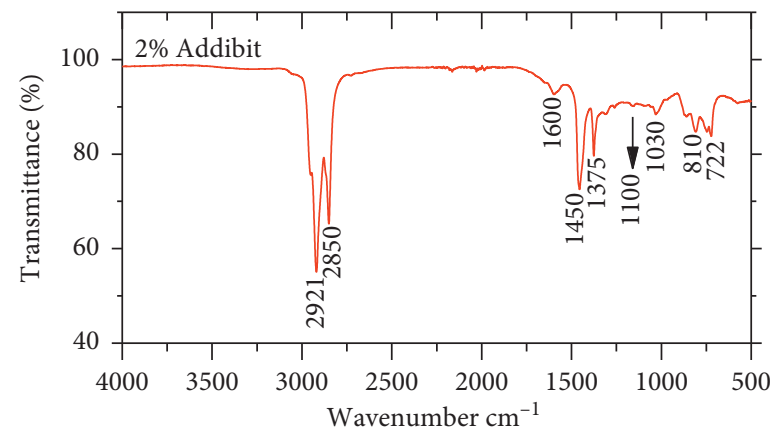

(d)

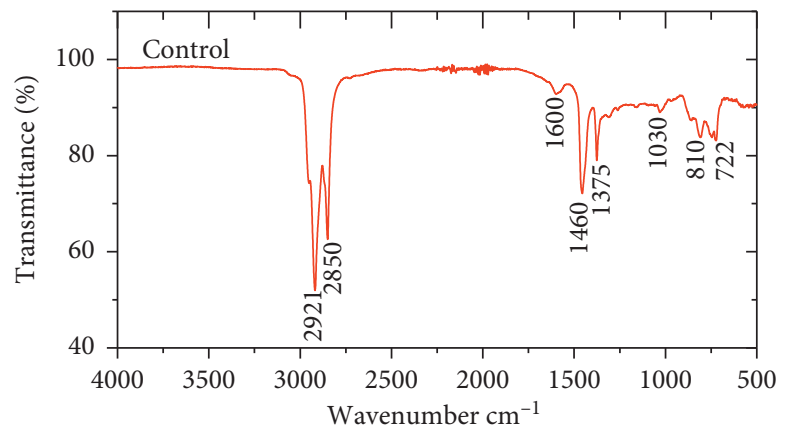

(e)

FIgURE 11: Infrared spectrum. (a) Tego XP additive. (b) Addibit additive. (c) CRM + 0.6\% Tego XP. (d) CRM + 2\% Addibit. (e) CRM control binders.

TABLE 6: FT-IR spectral data of CRM binders with and without WMA additives.

\begin{tabular}{|c|c|c|c|}
\hline Wavenumber $\mathrm{cm}^{-1}$ & Functional group & Literature value & Reference \\
\hline 2921,2850 & $-\mathrm{CH} 2$ and $-\mathrm{CH} 3$ stretching (Alkanes) & $2850-2960$ & {$[29],[55,56]$} \\
\hline 1600 & $-\mathrm{C}=\mathrm{C}$ stretching (Aromatics) & 1600 & {$[31],[55,56]$} \\
\hline 1460 & $\mathrm{CH} 2$ bending (aliphatic) & 1460 & [56] \\
\hline 1375 & $\mathrm{CH} 3$ bending (aliphatic) & 1375 & {$[56]$} \\
\hline 1100 & -Si-O-Si Asymmetric stretching & $1000-1100$ & {$[31,55]$} \\
\hline 1030 & $-\mathrm{S}=\mathrm{O}$ sulfoxide & 1030 & {$[56]$} \\
\hline 810,722 & $-\mathrm{C}-\mathrm{H}$ benzene ring & 810,722 & {$[29]$} \\
\hline
\end{tabular}

there exists a relationship between surface roughness and adhesion properties for bee-like structures. For the asphalt without bee-like structures, the adhesion properties of the material are dependent on the surface energies, which indicates the performance of the physical bond [58]. A reduction in surface roughness and surface energy of asphalt weakens the adhesion bonding between asphalt and rubber particles. The roughness index was determined from the NanoScope Analysis 1.9 software utilizing equation (18) given below: 


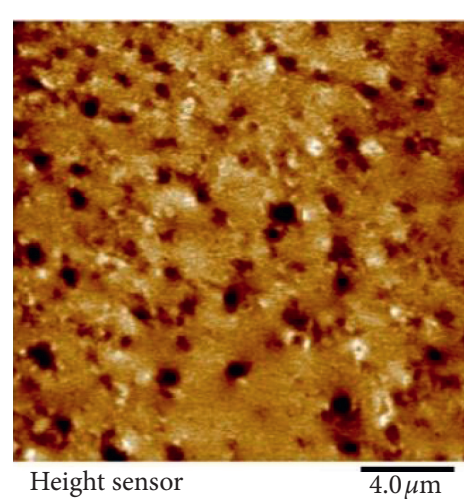

(A)

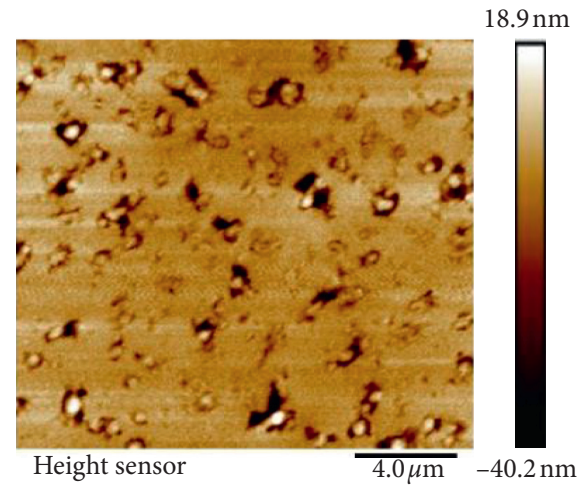

(A)

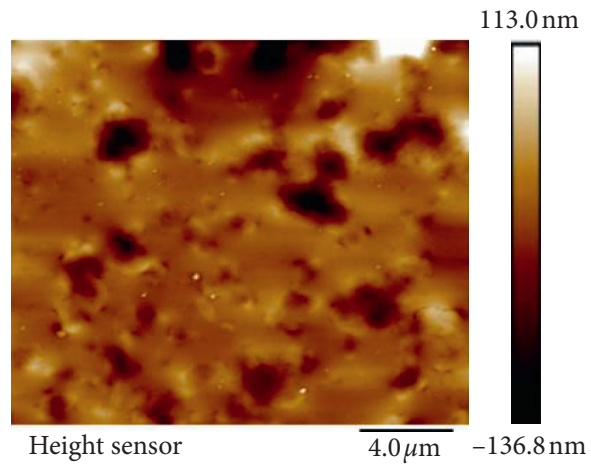

(A)

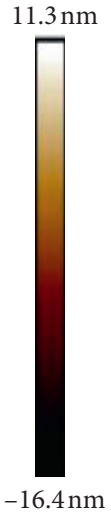

(a)

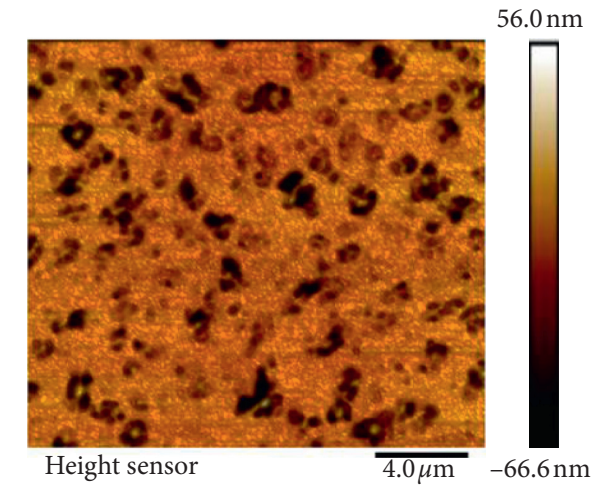

(B)

(b)

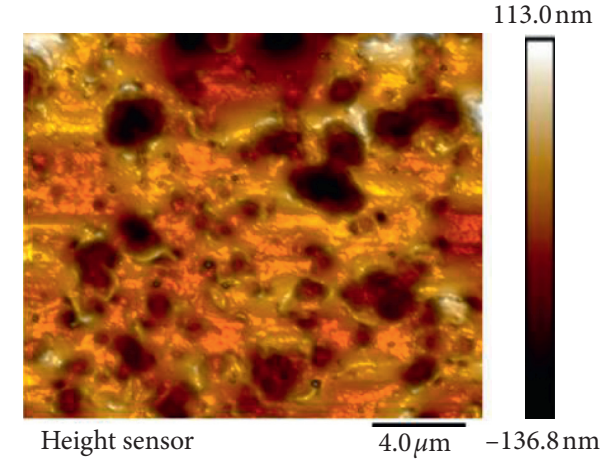

(B)

(c)

Figure 12: AFM images of asphalt binders of rubber asphalt binders. (A) Topographical image. (B) Phase image. (a) Rubberized Control binders, $\mathrm{Ra}=2.60 \mathrm{~nm}$. (A) Topographical image. (B) Phase image. (b) Rubberized binders with Tego Addibit, Ra=5.62 nm. (A) Topographical image. (B) Phase image. (c) Rubberized binders with Tego XP, Ra $=20.4 \mathrm{~nm}$.

$$
R a=\frac{1}{N} \sum_{j=1}^{N} Z_{i}
$$

As shown in Figure 12, the contrast in topography and phase images of binders indicate that a change in the microstructure of the asphalt samples occurred after incorporation of silicone WMA additives. Furthermore, the roughness of asphalt binder's microsurface increased with addition of WMA additives indicating that a change in microstructure resulted in roughening of asphalt's microsurface. Due to enhanced adhesion properties, the study established that CRM binders with Tego XP and Addibit additives could potentially improve resistance to moisture damage than CRM control binders due to increased surface roughness, which is an indicator of improved adhesion properties. 


\section{Conclusions}

This study investigated the influence of silicone-based warm mix additives on properties of CRM asphalt binders. In particular, morphology, rutting, and fatigue properties of CRM asphalt was studied from which the following conclusions were deduced:

(i) The addition of Tego XP and Addibit to CRM binder reduces its viscosity, which leads to a reduction in mixing, and laydown compaction of asphalt mixes. Furthermore, the viscosity reduction was more pronounced for binders with Addibit additive.

(ii) The addition of Tego XP to CRM binders increased the elasticity of the binder (as attested by $\mathrm{G}^{*} / \mathrm{Sin}(\delta)$ and phase angle $(\delta)$ ) thereby reducing the nonrecoverable compliance(Jnr) (as attested by MSCR test results). For these reasons, resistance to permanent deformation of CRM binders increased for binders containing Tego XP compared to control binders and those with Addibit additives.

(iii) CRM binders with Addibit exhibited improved fatigue resistance as compared to control binders and those with Tego XP additives. This result could be attributed to the softening effect of Addibit on CRM binders.

(iv) The IR absorption peaks for CRM binders containing both Tego XP and Tego Addibit showed characteristic absorption peaks of polydimethylsiloxane (PDMS). This was an indication that the WMA had silicone content, which is a wellknown hydrophobic or water repellent material that can improve resistance of binders to moisture damage.

(v) Incorporation of Tego XP and Tego Addibit in CRM binders increases surface roughness of rubber asphalt which can be correlated to improvement in bonding of rubber particles in asphalt matrix.

(vi) The conventional test results revealed that CRM binders with Tego XP had lower penetration values and higher softening point values, whereas binders with Addibit had lower softening point but high penetration values. In general, binders with Tego XP had lower temperature susceptibility as attested by the penetration index (PI) and hence could enhance rutting resistance.

The scope of this paper was limited to analysis of conventional tests, viscosity, rheology, rutting and fatigue cracking tests, chemical functional groups, and surface morphology. Future studies can explore low temperature performance of silicone-based WMA additives.

\section{Data Availability}

The data used to support the findings of the study are available from the corresponding author upon request.

\section{Conflicts of Interest}

The authors declare that they have no conflicts of interest.

\section{Acknowledgments}

The National Key R\&R Program of China (Grant no. 2018YFB1600100) and National Natural Science Foundation of China with Grant no. 51978219 funded this research.

\section{References}

[1] C. Akisetty, Evaluation of warm asphalt additives on the performance properties of crm binders and mixtures, $\mathrm{PhD}$ thesis, Clemson University, Clemson, SC, USA, 2008.

[2] Annual Book of ASTM Standards, Road and Paving Materials; Traveled Surface Characteristics, American Society for Testing Materials, West Conshohocken, PA, USA, 2005.

[3] L. D. Presti, "Recycled tyre rubber modified bitumens for road asphalt mixtures: a literature review," Construction and Building Materials, vol. 49, pp. 863-881, 2013.

[4] A. M. Rodríguez-Alloza, J. Gallego, I. Pérez, A. Bonati, and F. Giuliani, "High and low temperature properties of crumb rubber modified binders containing warm mix asphalt additives," Construction and Building Materials, vol. 53, p. 460, 2014.

[5] L. P. T. L. Fontes, G. Trichês, J. C. Pais, and P. A. A. Pereira, "Evaluating permanent deformation in asphalt rubber mixtures," Construction and Building Materials, vol. 24, pp. 1193-1200, 2010.

[6] H. I. Ozturk and F. Kamran, "Laboratory evaluation of dry process crumb rubber modified mixtures containing Warm Mix Asphalt Additives," Construction and Building Materials, vol. 229, Article ID 116940, 2019.

[7] V. Venudharan, K. P. Biligiri, and N. C. Das, "Investigations on behavioral characteristics of asphalt binder with crumb rubber modification: rheological and thermo-chemical approach," Construction and Building Materials, vol. 181, p. 455, 2018.

[8] M. R. Pouranian, M. A. Notani, M. T. Tabesh, B. Nazeri, and M. Shishehbor, "Rheological and environmental characteristics of crumb rubber asphalt binders containing nonfoaming warm mix asphalt additives," Construction and Building Materials, vol. 238, 2020.

[9] A. M. Rodríguez-Alloza, J. Gallego, and I. Pérez, "Study of the effect of four warm mix asphalt additives on bitumen modified with 15\% crumb rubber," Construction and Building Materials, vol. 43, pp. 300-308, 2013.

[10] B. Huang, L. N. Mohammad, P. S. Graves, and C. Abadie, "Louisiana experience with crumb rubber-modified hot-mix asphalt pavement," Transportation Research Record: Journal of the Transportation Research Board, vol. 1789, no. 1, pp. 1-13, 2002.

[11] H. Yu, Z. Leng, F. Xiao, and Z. Gao, "Rheological and chemical characteristics of rubberized binders with nonfoaming warm mix additives," Construction and Building Materials, vol. 111, pp. 671-678, 2016.

[12] C. K. Akisetty, S.-J. Lee, and S. N. Amirkhanian, "Effects of compaction temperature on volumetric properties of rubberized mixes containing warm-mix additives," Journal of Materials in Civil Engineering, vol. 21, no. 8, pp. 409-415, 2009. 
[13] C. Akisetty, F. Xiao, T. Gandhi, and S. Amirkhanian, "Estimating correlations between rheological and engineering properties of rubberized asphalt concrete mixtures containing warm mix asphalt additive," Construction and Building Materials, vol. 25, no. 2, p. 950, 2011.

[14] C. K. Akisetty, S. J. Lee, W. Rogers, and S. N. Amirkhanian, "Evaluation of engineering properties of rubberized laboratory mixes containing warm mix additives," Journal of Testing and Evaluation, vol. 38, no. 1, Article ID 102319, 2010.

[15] T. Gandhi, C. Akisetty, and S. A. Amirkhanian, "Comparison of warm asphalt binder aging with laboratory aging procedures," Journal of Testing and Evaluation, vol. 38, no. 1, Article ID 101934, 2010.

[16] C. K. Akisetty, T. Gandhi, S.-J. Lee, and S. N. Amirkhanian, "Analysis of rheological properties of rubberized binders containing warm asphalt additives," Canadian Journal of Civil Engineering, vol. 37, no. 5, p. 763, 2010.

[17] X. Yang, Z. You, D. Perram et al., "Emission analysis of recycled tire rubber modified asphalt in hot and warm mix conditions," Journal of Hazardous Materials, vol. 365, Article ID 942951, 2019.

[18] A. Rajagopal, Comparison and Definition of State DOT's Practices in Selection of Materials for Pavements, Federal Highway Administration, Washington, DC, USA, 2004.

[19] T. Gandhi, C. Akisetty, and S. Amirkhanian, "Laboratory evaluation of warm asphalt binder aging characteristics," International Journal of Pavement Engineering, vol. 10, no. 5, p. 353, 2009.

[20] H. S. Kim, S. J. Lee, and S. Amirkhanian, "Effects of warm mix asphalt additives on performance properties of polymer modified asphalt binders," Canadian Journal of Civil Engineering, vol. 37, no. 1, pp. 17-24, 2010.

[21] J. Gong, Y. Liu, Q. Wang et al., "Performance evaluation of warm mix asphalt additive modified epoxy asphalt rubbers," Construction and Building Materials, vol. 204, p. 288, 2019.

[22] A. M. Rodríguez-Alloza and J. Gallego, "Mechanical performance of asphalt rubber mixtures with warm mix asphalt additives," Materials and Structures, vol. 50, p. 147, 2017.

[23] B. G. Koenders, D. A. Stoker, P. Brown et al., Innovative Process in Asphalt Production and Application to Obtain Lower Operating Temperatures, 2nd Eurasphalt \& Eurobitumen Congress, Barcelona, Spain, 2000.

[24] Eurovia Services Website: http://www.eurovia.com/en/ produit/135.aspx.

[25] Sasol Wax Website: http://www.sasolwax.com/Sasobit_ Technology.html.

[26] C. K. Akisetty, S.-J. Lee, and S. N. Amirkhanian, "High temperature properties of rubberized binders containing warm asphalt additives," Construction and Building Materials, vol. 23, no. 1, p. 565, 2009.

[27] H. Wang, Z. Dang, Z. You, and D. Cao, "Effect of warm mixture asphalt (WMA) additives on high failure temperature properties for crumb rubber modified (CRM) binders," Construction and Building Materials, vol. 35, 2012.

[28] F. Xiao, P. E. Wenbin Zhao, and S. N. Amirkhanian, "Fatigue behavior of rubberized asphalt concrete mixtures containing warm asphalt additives," Construction and Building Materials, vol. 23, no. 10, p. 3144, 2009.

[29] Q. Yang and X. Li, "Mechanism and effectiveness of a siliconebased warm mix additive," Journal of Materials in Civil Engineering, vol. 31, no. 1, Article ID 04018336, 2019.

[30] I. Omari, "Effects of two warm-mix additives on aging, rheological and failure properties of asphalt cements," MSc Thesis, Queen's University, Kingston, Canada, 2014.
[31] Z.-j. Dong, T. Zhou, H. Luan, R. C. Williams, P. Wang, and Z. Leng, "Composite modification mechanism of blended bioasphalt combining styrene-butadiene-styrene with crumb rubber: a sustainable and environmental-friendly solution for wastes," Journal of Cleaner Production, vol. 214, p. 593, 2019.

[32] Evonik Industries, 2020, http://www.evonik.com/.

[33] M. A. Abdelrahman and S. H. Carpenter, "Mechanism of the interaction of asphalt cement with crumb rubber modifier," Transportation Research Record: Journal of the Transportation Research Board, vol. 1661, pp. 106-113, 1999.

[34] S. Wang, D. Cheng, and F. Xiao, "Recent developments in the application of chemical approaches to rubberized asphalt," Construction and Building Materials, vol. 131, pp. 101-113, 2017.

[35] H. Wang, P. Apostolidis, J. Zhu, X. Liu, A. Skarpas, and S. Erkens, "The role of thermodynamics and kinetics in rubber-bitumen systems: a theoretical overview," International Journal of Pavement Engineering, 2020.

[36] W. H. Daly, S. S. Balamurugan, I. Negulescu et al., "Characterization of crumb rubber modifiers after dispersion in asphalt binders," Energy \& Fuels, vol. 33, no. 4, p. 2665, 2018.

[37] Y.-O. Tu and A. C. Ouano, "Model for the kinematics of polymer dissolution," IBM Journal of Research and Development, vol. 21, no. 2, pp. 131-142, 1977.

[38] P. J. Flory and J. Rehner Jr., "Statistical mechanics of cross-linked polymer networks II. Swelling," The Journal of Chemical Physics, vol. 11, no. 11, p. 521, 1943.

[39] M. Stroup-Gardiner, D. E. Newcomb, and B. Tanquist, "Asphaltrubber interactions," Transportation Research Record, vol. 141799 pages, 1993.

[40] I. Artamendi and H. A. Khalid, "Diffusion kinetics of bitumen into waste tyre rubber," Journal of the Association of Asphalt Paving Technologists, vol. 75, pp. 133-164, 2006.

[41] L. Zanzotto and G. J. Kennepohl, "Development of rubber and asphalt binders by depolymerization and devulcanization of scrap tires in asphalt," Transportation Research Record: Journal of the Transportation Research Board, vol. 1530, no. 1, p. $51,1996$.

[42] N. Tang, W. Huang, and F. Xiao, "Chemical and rheological investigation of High-cured crumb rubber-modified asphalt," Construction and Building Materials, vol. 123, p. 847, 2016.

[43] H. Yao, S. Zhou, and S. Wang, "Structural evolution of recycled tire rubber in asphalt," Journal of Applied Polymer Science, vol. 133, no. 6, pp. 1-7, 2016.

[44] Lo. D. Presti, M. A. Izquierdo, and A. Carrión Del Barco Jiménez, "Towards storage-stable high-content recycled tyre rubber modified bitumen," Construction and Building Materials, vol. 172, pp. 106-111, 2018.

[45] G. Baumgardner and J. D'Angelo, "Transportation research," Record: Journal of the Transportation Research Board, vol. 2293, pp. 73-79, 2012.

[46] J. P. Pfeiffer and P. M. Van Doormaal, "The rheological properties of asphaltic bitumens," Journal of the Institution of Petroleum Technologists, vol. 22, pp. 414-440, 1936.

[47] A. Diab, Z. You, X. Li, J. C. Pais, X. Yang, and S. Chen, "Rheological models for non-Newtonian viscosity of modified asphalt binders and mastics," Egyptian Journal of Petroleum, vol. 29, no. 2, p. 105, 2020.

[48] Anonymous. https://pavementinteractive.org/reference-desk/ testing/binder-tests/dynamic-shear-rheometer/.

[49] A. Behnood, A. Shah, R. S. McDaniel, and J. Olek, "Analysis of the multiple stress creep recovery asphalt binder test and specifications for use in indiana," FHWA/IN/JTRP-2016/07, 
Indiana Department of Transportation, West Lafayette, Indiana, 2016.

[50] C. Wang, C. Castorena, J. Zhang, and Y. Richard Kim, "Unified failure criterion for asphalt binder under cyclic fatigue loading," Road Materials and Pavement Design, vol. 16, no. 2, pp. 125-148, 2015.

[51] R. A. Schapery, "Correspondence principles and a generalizedJ integral for large deformation and fracture analysis of viscoelastic media," International Journal of Fracture, vol. 25, no. 3, pp. 195-223, 1984.

[52] H. Wang, X. Liu, P. Apostolidis, S. Erkens, and A. Skarpas, "Experimental investigation of rubber swelling in bitumen," Transportation Research Record: Journal of the Transportation Research Board, vol. 2674, no. 2, p. 203, 2020.

[53] L. D. Presti and G. Airey, "Tyre rubber-modified bitumens development: the effect of varying processing conditions," Road Materials and Pavement Design, vol. 14, no. 4, pp. 888-900, 2013.

[54] M. Ragab, M. Abdelrahman, and A. Ghavibazoo, "Performance enhancement of crumb rubber-modified asphalts through control of the developed internal network structure," Transportation Research Record: Journal of the Transportation Research Board, vol. 2371, no. 1, pp. 96-104, 2013.

[55] J. Lin, M. Chen, and S. Wu, "Utilization of silicone maintenance materials to improve the moisture sensitivity of asphalt mixtures," Construction and Building Materials, vol. 33, pp. 1-6, 2012.

[56] National Academies of Sciences and Engineering, and Medicine, Relationship between Chemical Makeup of Binders and Engineering Performance, The National Academies Press, Washington, DC, USA, 2017.

[57] Y. Junyan, X. Pang, D. Yao, X. Meng, and D. Feng, "Characterization of surface roughness and adhesive mechanism of asphalt and mineral aggregate based on atomic force microscopy method," Acta Metallurgica Composites Sinica, vol. 34, no. 5, pp. 1111-1121, 2017.

[58] Z. Wang, L. Wang, C. Li, and M. Ren, "Microstructure and mechanical properties of polyphosphoric acid modified asphalt," IOP Conference Series: Earth and Environmental Science, vol. 304, no. 5, Article ID 052031, 2019. 